Review

\title{
Livestock Hydatid Disease (Cystic Hydatidosis) in Libya: A Review
}

\author{
${ }^{1}$ Mohamed M. Ibrahem, ${ }^{2}$ Wafa M. Ibrahem, ${ }^{3}$ Mostafa M. Abdorrahem and ${ }^{4}$ Kawther M. Ibrahem \\ ${ }^{1}$ Department of Zoology, Faculty of Science, University of Zawia, P.O. Box 16418, Zawia, Libya \\ ${ }^{2}$ Department of Parasitology, Faculty of Medicine, University of Zawia, P.O. Box 16418, Zawia, Libya \\ ${ }^{3}$ Department of Biology, Faculty of Education-BaniWalid, Azzytuna University, P.O. Box 13227, Tripoli, Libya \\ ${ }^{4}$ Department of Chemistry, Faculty of Pharmacy, University of Zawia, P.O. Box 16418, Zawia, Libya
}

\author{
Article history \\ Received: 15-01-2016 \\ Revised: 13-02-2016 \\ Accepted: 11-04-2016 \\ Corresponding Author: \\ Mohamed M. Ibrahem \\ Department of Zoology, \\ Faculty of Science, University \\ of Zawia, P.O. Box 16418, \\ Zawia, Libya \\ Email: masoudibrahem@gmail.com
}

\begin{abstract}
Cystic hydatid disease is an infection caused by the larval stage of a cestode parasite called Echinococcus granulosus. Hydatid cysts are one of the major parasitic infections in Libya that causes many health problems to human and responsible for economic losses because of the condemnation of the slaughtered animals infected viscera as well as reducing the quality and quantity of the livestock other productions such as milk, wool and meat. Many abattoir investigations in Libya have revealed that, cystic hydatidosis is a disease which infect a wide range of animal species with variable rates of infection, for example, sheep (1.6 to $40 \%$ ), goats (5.6 to $70 \%$ ), cattle (2.7 to $56 \%$ ) and camels (2.7 to $48 \%$ ). Based on the available abattoirs data, cystic echinococcosis in livestock can be classified as hyper endemic in the country as the infection rate in all animal species reached almost $50 \%$ or over which fulfill the WHO criteria. Because of the absence of accurate and updated government records in all abattoirs, it is difficult to estimate the exact economic losses due to cystic hydatidosis in livestock. Diagnosis of the parasite larval stage (hydatid disease) in the living intermediate hosts (ante mortem) is basically by using imaging and serological methods, while after slaughtering the animals (post mortem), the examination of hydatid cysts can be by inspection of several expected infected organs mainly liver and lungs and to some extent other organs including spleen, kidneys, heart, brain and bones of the animal carcasses. Prevention of cystic hydatid disease primarily focusing on veterinary investigations for controlling the extent and the intensity of echinococcosis in the definitive host populations, which indirectly may lead to control the prevalence of hydatid disease in the intermediate host animals. Treatment of cystic hydatidosis in livestock is still under investigation but anti-helminthes drugs can be used. Regular treatment, taking high degree of precautions when handling pets or dealing with animal meat must be taken into consideration to minimize the level of infection and egg excretion as well as the vaccination of ruminant intermediate hosts, are all in evaluation.
\end{abstract}

Keywords: Cystic Hydatidosis, Dogs, Echinococcosis, Libya, Livestock, Prevalence

\section{Introduction}

Cystic Echinococcosis (CE), cystic hydatid disease, or cystic hydatidosis all are terms used to identify infection caused by a tape worm parasite called Echinococcus granulosus. CE is a zoonosis and has been reported to occur in all continents of the world. The highest level of cystic hydatid disease recorded in South
America, the Mediterranean region including North Africa, Eastern Europe, the Middle East and Far East countries, (Fig. 1), (Eckert et al., 2001a). To complete its life cycle, the parasite needs two mammalian animals (hosts); the first is a definitive host, which is usually a domestic/wild carnivore for the adult stage of the parasite and the second is an intermediate host, which is usually domestic/wild ungulates for the larval 
(hydatid cyst) stage (Fig. 2). Various species of livestock in Libya known to harbour hydatid cysts such as sheep, goats, cattle and camels, however, these species are the main sources of infection with echinococcosis in dogs. Other animals can be acting as intermediate hosts such as horses, donkeys, pigs, etc. also involved in the life cycle in many other parts of the world (Dalimi et al., 2002; Lahmar et al., 2004; Daryani et al., 2006; Acosta-Jamett et al., 2010).

The adult stage of the parasite is approximately 3-7 $\mathrm{mm}$ long with typically three segments as well as other cestode morphological features and characteristics which help in species diagnosis (Fig. 3A), (Thompson, 1995). The parasite lives attached to the small intestinal wall of a carnivore definitive host using their hooks and in this place, adult worms produce a large number of eggs (Fig. 3B), which are periodically shed in the faeces and scattered in the environment by birds, insects, wind and water. Eggs also can be carried by uninfected pets on their fur if they get contact to the faeces of infected wild hosts and this is possibly more common in dogs which may roll on contaminated ground and therefore, they become a source of infection to the intermediate hosts. Intermediate hosts became infected when they ingest viable eggs in their foods such as vegetables, fruits and herbs, or drunk in contaminated water or through contaminated hands in case of human hydatidosis for example, pets an infected dogs or cats, handles an infected wild animals or its carcasses, touches contaminated soil with the parasite eggs.
Once the eggs ingested by a suitable intermediate host, they hatch in the duodenum releasing their hexacanth embryos (the oncospheres) which immediately penetrate the intestinal wall towards the mesenteric vessels where they picked up and carried by blood stream to the major filtering organs mainly liver and lungs. Other sites like abdominal wall, brain, kidneys bones, muscles and orbits may also be involved (Polat et al., 2003; Bal et al., 2008). The oncospheres requires about one year time to transform and develop into full larval hydatid cysts (Fig. 3C) with a numerous tiny tapeworm heads called protoscoleces that are formed via asexual reproduction (Fig. 3D).

The parasite life cycle to be completed, viable hydatid cysts containing fully developed protoscoleces must be ingested by dogs the definitive hosts and the released protoscoleces then attached themselves to the dog's intestinal lining and start to develop into mature adult tapeworms within 25-80 days depending on the species and the parasite strain. Infected human is the 'dead-end' host for E. granulosus, since the life cycle of the parasite is usually completed when carnivores are getting access to infected herbivores organs (McManus et al., 2003; Zhang et al., 2003). There may be exceptional circumstances when infected human could also serve to complete the parasite life cycle, for example in some countries in Africa especially in the war regions, where killed people remained unburied for long time and therefore, dogs and other wild carnivores can access to those dead bodies (Macpherson et al., 1983).

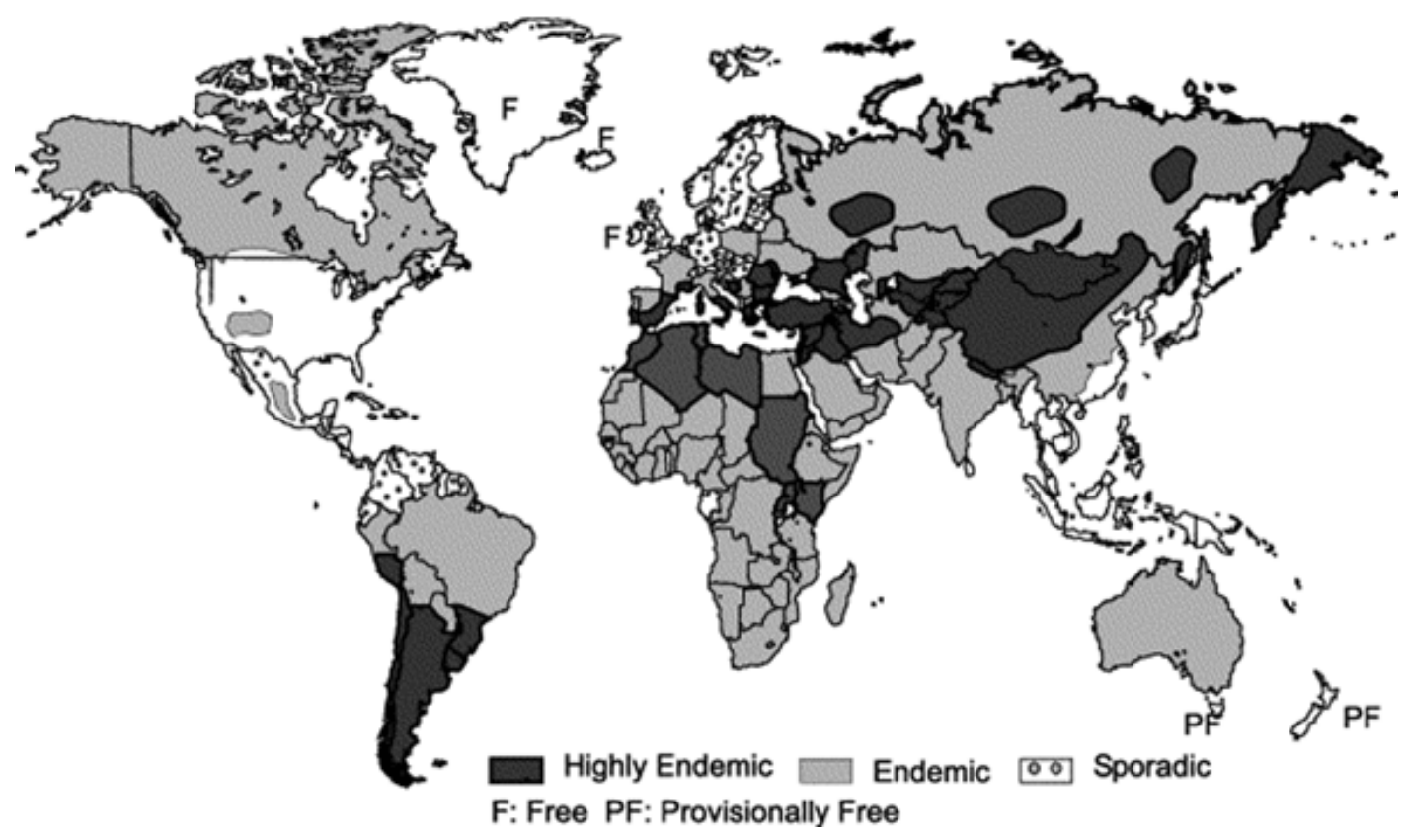

Fig. 1. Geographical distribution of E. granulosus. The highest frequency of cystic hydatid disease (E. granulosus) is in South America, North Africa, the Mediterranean littoral, Eastern Europe and the Middle and Far East (Adapted from Eckert and Deplazes, 2004) 


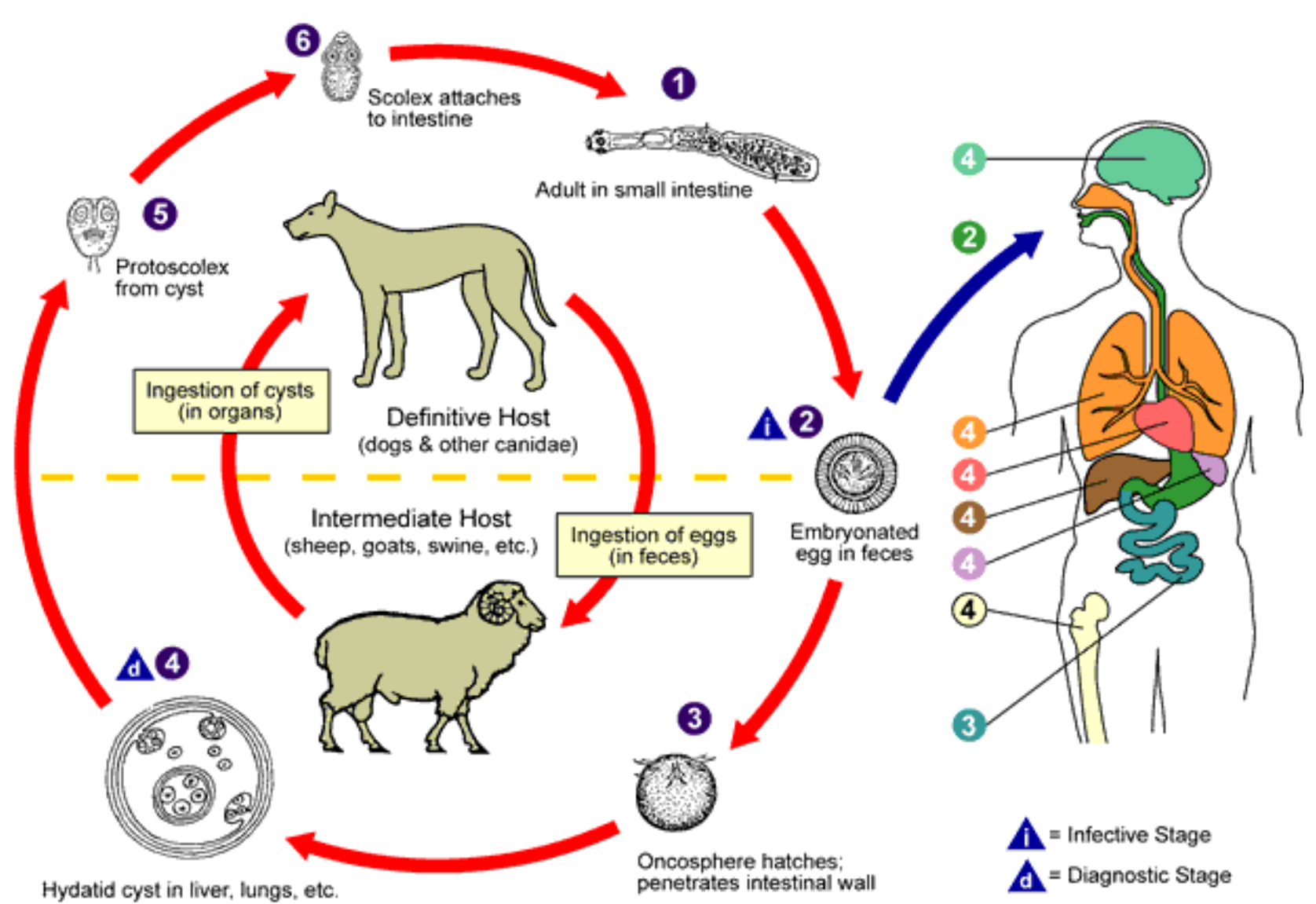

Fig. 2. The adult Echinococcus granulosus 1 resides in the small bowel of the definitive hosts, dogs or other canids. Gravid proglottids release eggs 2 that are passed in the feces. After ingestion by a suitable intermediate host (sheep, goat, swine, cattle, horses, camel), the egg hatches in the small bowel and releases an oncosphere 3 that penetrates the intestinal wall and migrates through the circulatory system into various organs, especially the liver and lungs. In these organs, the oncosphere develops into a cyst 4 that enlarges gradually, producing protoscolices and daughter cysts that fill the cyst interior. The definitive host becomes infected by ingesting the cyst-containing organs of the infected intermediate host. After ingestion, the protoscolices 5 evaginate, attach to the intestinal mucosa $\mathbf{6}$ and develop into adult stages $\mathbf{1}$ in 32 to 80 days. 2 Humans can become infected on the same way of livestock, 3 hatched oncospheres in the small intestine, 444444 the possible infected organs (courtesy of DPDx)

The aim of our review is to describe the prevalence and history of hydatid disease in livestock along the past few decades in Libya. The review also discusses aspects of the parasite life cycle, transmission, risk factors, economic importance, improved diagnosis, treatment and control and prevention of the disease.

\section{Prevalence and the History of Hydatid Disease in Livestock}

Cystic echinococcosis in livestock was first reported in Libya by Medulla (1931) who stated that, CE is common in camels. Three decades later, Cicogna (1961) made a study on the prevalence of hydatid disease in sheep and cattle around Tripoli area and reported that, 40 and $70 \%$ of the examined animals were infected with hydatid disease respectively, (Table 1). Abattoir data collected from Benghazi area eastern of the country from 1975 to 1977 , indicated that, the rate of infection with $\mathrm{CE}$ in imported animals was $0.8 \%$ in sheep, $0.0 \%$ in goats, $3.1 \%$ in cattle and $20 \%$ in camels; while in local reared animals, the rate of infection with CE was $2.7 \%$ in sheep, $7.9 \%$ in goats, $11.2 \%$ in cattle and $16.1 \%$ in camels, (Table 2), (Gebreel et al., 1983). Similar study has been carried out in Tripoli area and the obtained abattoir data on CE in imported animals were $25.8 \%$ in sheep, $3.8 \%$ in cattle and $26.4 \%$ in camels, while in local reared animals, the infection rate was $4.3 \%$ in sheep, $6.6 \%$ in cattle and $27.2 \%$ in camels, (Table 1), (Aboudaya, 1985). Two years later, Gusbi et al. (1987) examined 5118 sheep at ten abattoirs around the country and found that, $7.85 \%$ of the inspected animals were 
infected with hydatid disease, among this number $12.74 \%$ were adults and $0.29 \%$ were lambs (Table 4). Gusbi et al. (1990) also conducted an extensive study on CE in other livestock including 2295 goats, 1023 cattle and 998 camels from 14 abattoirs around the country and reported that, $1.5,5.4$ and $35.9 \%$ respectively were infected with

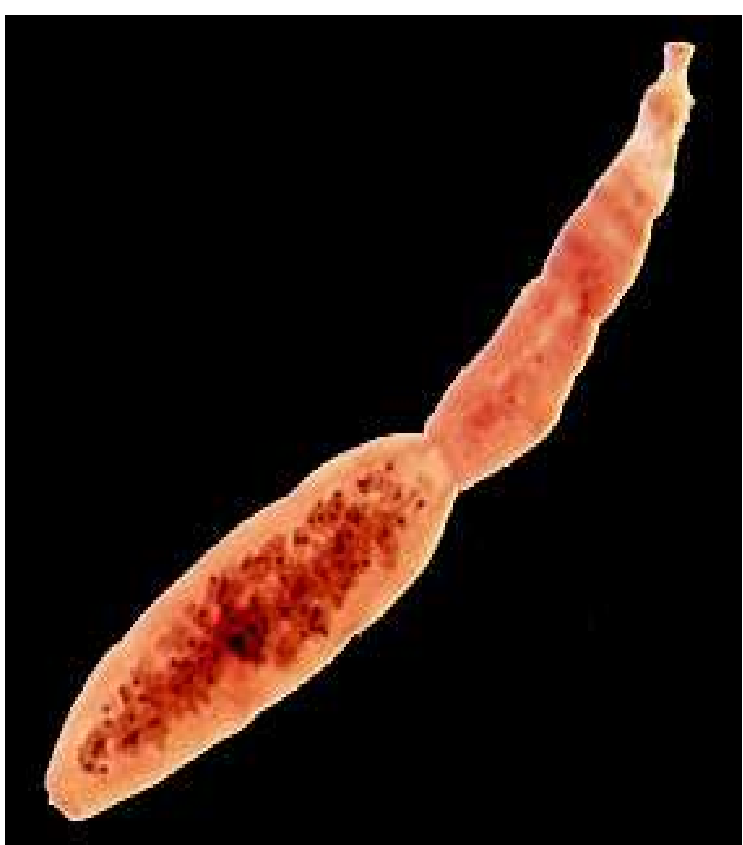

(A)

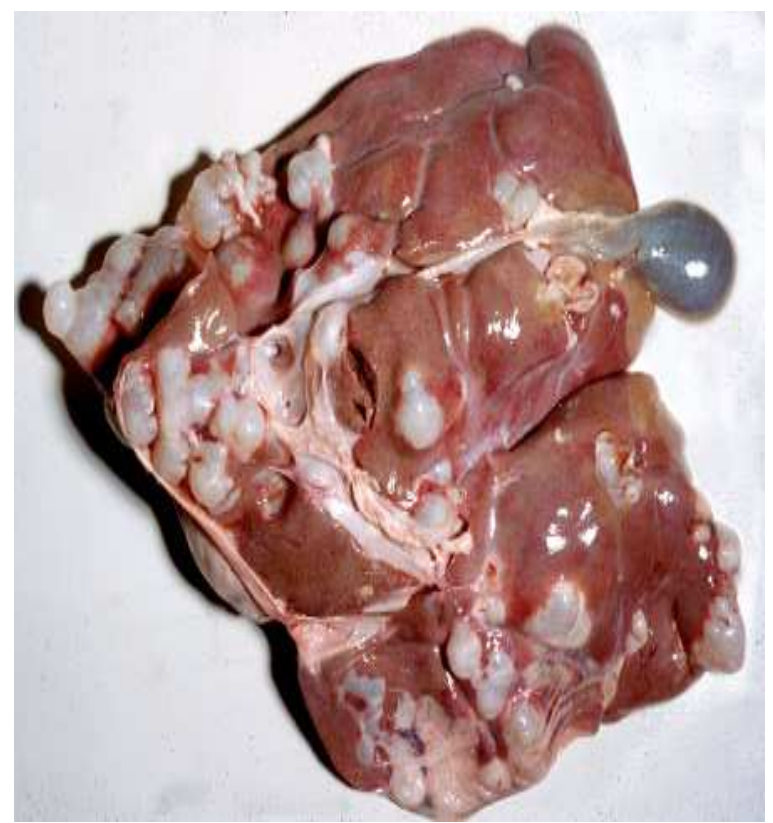

(C) hydatid disease (Table 4). Eight years later, Ibrahem and Craig (1998) examined 514 camels, 367 sheep and 184 goats slaughtered in six abattoirs at Zawia, Tripoli, ElKhumes, Misurata, Sirt and Benghazi abattoirs and found that, $15.8,3.8$ and $48 \%$, of sheep, goats and camels, respectively were infected with CE (Table 4).

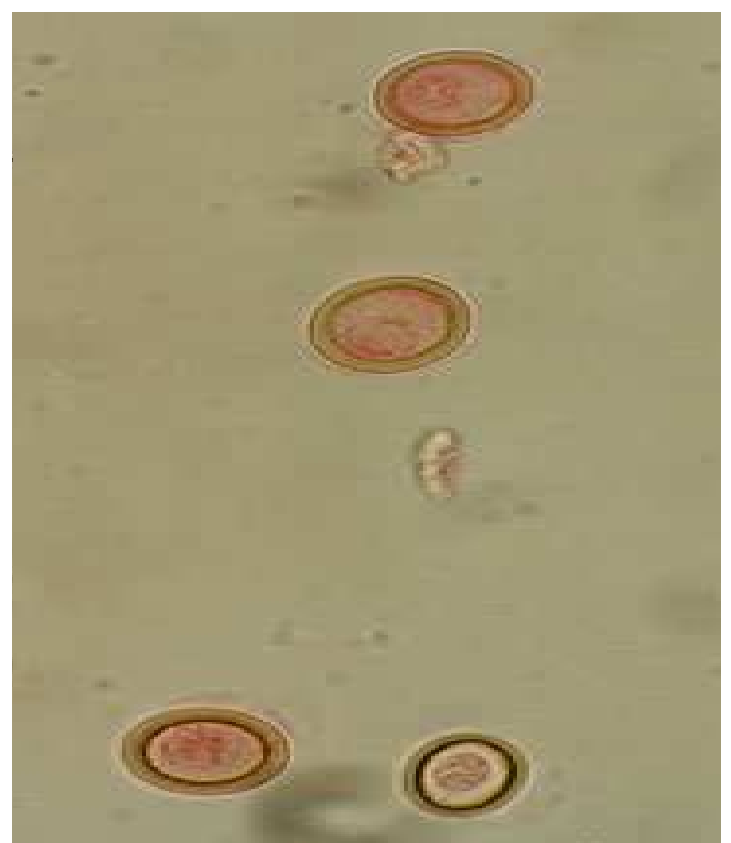

(B)

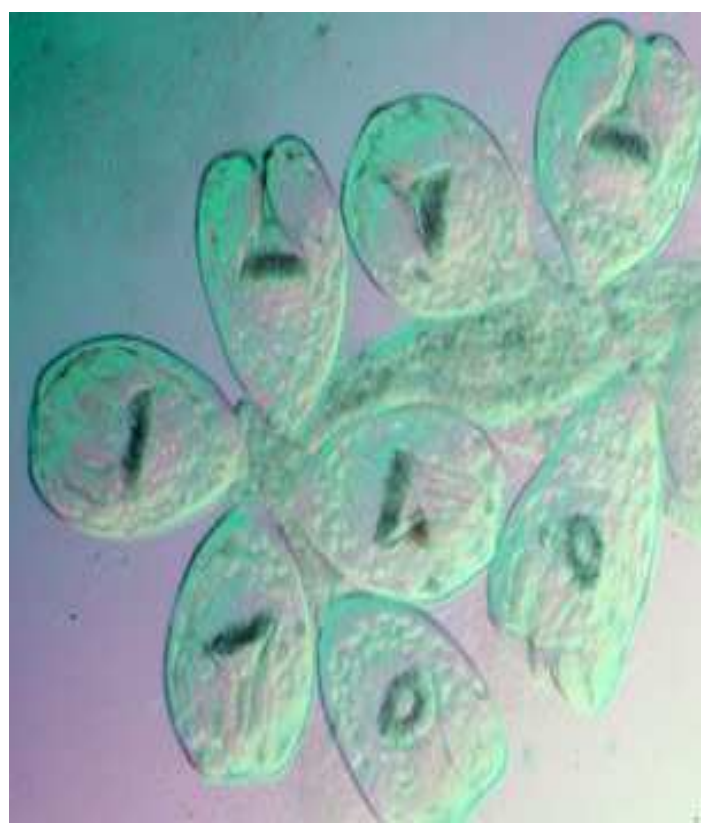

(D)

Fig. 3.Illustrations showing: (A) Whole mount of adult E. granulosus worm, (B) Taeniid species eggs, (C) Heavily infected sheep liver with hydatid disease and (D) Protoscoleces from human infected liver, (A, C and D from Dr. John Walker, Sydney Medical School, University of SYDNEY and B from Jesper Monrad and Christina Thoisen Department of Veterinary Disease Biology, Faculty of Life Sciences - University of Copenhagen, Denmark) 
Mohamed M. Ibrahem et al. / American Journal of Animal and Veterinary Sciences 2016, 11 (2): 70.84 DOI: 10.3844/ajavsp.2016.70.84

Table 1. Abattoir data on the prevalence of cystic hydatidosis in livestock from Tripoli region

\begin{tabular}{lcc}
\hline Animal species & Prevalence (\%) & Reference \\
\hline Sheep & 40.0 & Cicogna (1961) \\
Cattle & 70.0 & Aboudaya (1985) \\
Sheep (imported) & 25.8 & \\
Cattle = & 3.8 & \\
Camels $=$ & 26.4 & \\
Sheep (local) & 4.3 & \\
Cattle $=$ & 6.6 & \\
Camels $=$ & 27.2 & \\
\hline
\end{tabular}

Table 2. Abattoir data on the prevalence of cystic hydatidosis in livestock from Benghazi, Al-Jabel Al-Akhder (Shahat) and Bayada regions

\begin{tabular}{|c|c|c|}
\hline Animal species & Prevalence $(\%)$ & Reference \\
\hline Sheep (imported)* & 0.80 & Gebreel et al. (1983) \\
\hline Goats $=$ & 0.00 & \\
\hline Cattle $=$ & 3.10 & \\
\hline Camels $=$ & 20.00 & \\
\hline Sheep (local) & 2.70 & \\
\hline Goats $=$ & 7.90 & \\
\hline Cattle $=$ & 11.20 & \\
\hline Camels $=$ & 16.10 & \\
\hline Sheep* & 20.00 & Tashani et al. (2002) \\
\hline Goats & 3.40 & \\
\hline Camels & 13.60 & \\
\hline Cattle & 11.00 & \\
\hline Sheep** & 8.70 & Al-Khalidi (1998) \\
\hline Goats & 5.40 & \\
\hline Cattle & 6.40 & \\
\hline Camels & 35.00 & \\
\hline Sheep*** & 56.00 & Ekhnefer (2014) \\
\hline Goats & 40.00 & \\
\hline Cattle & 28.57 & \\
\hline \multicolumn{3}{|c|}{ *Data from Benghazi region, ${ }^{* *}$ Data from Al-Jabel Al-Akhder (Shahat) region, $* * *$ Data from Bayada region } \\
\hline Animal species & Prevalence $(\%)$ & Reference \\
\hline Sheep* & 16.75 & Elmajdoub et al. (2007) \\
\hline Cattle & 14.62 & \\
\hline Camels & 12.96 & \\
\hline Camels* & 3.62 & Kassem and Gdoura (2006) \\
\hline Sheep** & 4.90 & Kassem et al. (2013) \\
\hline Goats & 2.40 & \\
\hline Camels & 2.70 & \\
\hline Cattle & 15.00 & \\
\hline
\end{tabular}

*Data from Misrata region, **Data from Sirt region

Table 4. Abattoir data on the prevalence of cystic hydatidosis in livestock from 30 slaughterhouses around the country

\begin{tabular}{lll}
\hline Animal species & Prevalence (\%) & Reference \\
\hline Sheep & 7.85 & Gusbi et al. $(1987)$ \\
Goats & $1.5 \%$ & Gusbi et al. $(1990)$ \\
Cattle & $5.4 \%$ & \\
Camels & $35.9 \%$ & Ibrahem and Craig (1998) \\
Sheep & 15.8 & \\
Goats & 3.8 & Elmajdoub and Rahman (2015) \\
Camels & 48 & \\
Sheep & 10.52 & \\
Camels & 12.54 & \\
Cattle & 10.56 &
\end{tabular}


In the same year but further eastern of the country, data from Shahat abattoir, Al-Jabal Al-Akhdar indicated that, 48/554(8.7\%), 18/338(5.4\%), 8/124(6.4\%) and $14 / 40(35 \%)$ of examined sheep, goats, cattle and camels respectively were infected with hydatid cysts, (Table 2), (Al-Khalidi, 1998). Few years later, Tashani et al. (2002) examined 1087 sheep, 881 goats, 428 camels and 614 cattle at post mortem in Benghazi abattoirs eastern of the country and found that, 20, 3.4, 13.6 and $11 \%$, respectively were infected with CE (Table 2). Kassem and Gdoura (2006) examined 1380 local bred camels (Camelus dromedaries) slaughtered at Sirt abattoirs middle of the country and found that, $3.62 \%$ of the animals were infected with hydatid cysts (Table 3 ). One year later, investigation on the prevalence of $\mathrm{CE}$ in livestock was conducted by Elmajdoub et al. (2007) at Misurata abattoirs about $200 \mathrm{Km}$ east of Tripoli the capital; the obtained results showed that, $16.75 \%$ of 6935 sheep, $14.62 \%$ of 1901 cattle and $12.96 \%$ of 1863 camels were infected with hydatid cysts (Table 3 ). In a recent study, also from Sirt abattoirs, Kassem et al. (2013), published data on CE in sheep, goats, camels and cattle, the data indicated that, 4.9, 2.4, 2.7 and 15\% of examined sheep, goats, camels and cattle respectively were infected with hydatid cysts (Table 3). Further eastern of the country again, data collected from Bayada city abattoirs (Alkhlele and Atellal) showed that, 56\%, 40 and $28.57 \%$ of examined sheep (715), goats (500) and cattle (350) respectively were infected with hydatid cysts, (Table 2), (Ekhnefer, 2014). Lastly, a study by Elmajdoub and Rahman (2015) who examined 32,971 livestock animals including 25314 sheep, 7496 camels and 161 cattle from different government abattoirs all around the country, the overall prevalence rate of infection with CE was $10.06 \%$ and among the individual group of animals, the rate of infection with cystic hydatidosis was $10.52 \%$ in sheep, $12.54 \%$ in camels and $10.56 \%$ in cattle (Table 4). Blood samples from 214 lambs, 2030 sheep and 364 goats originally from the north west of Libya, naturally exposed to the infection with CE were tested serologically for the presence of anti-hydatid antibodies using camel AgB in ELISA and the obtained results were 18,60 and $27 \%$ of lambs, sheep and goats respectively were seropositive, (Table 4), (Ibrahem and Ibrahem, 2015). The reported differences in the rate of prevalence of CE between the different areas and also between the different intermediate hosts could be due to the differences in the environmental factors effecting the parasite eggs, such as temperature, humidity and the nature of the pasture between those areas as well as the existence of different strains of E. granulosus morphologically and biochemically adapted to each farm species (Fromsa and Jobre, 2011). Such differences are agreed to those reported from other African countries (Njoroge et al., 2002; Ernest et al., 2009).
Significant seasonal variations in the prevalence of cystic hydatidosis were also recorded through Libyan abattoir meat inspection and this could be due to the differences in the environmental conditions between the different areas of the country along the different seasons, (Elmajdoub and Rahman, 2015) and these findings agreed to those reported in other countries (Ansari-Lari, 2005; Ibrahim, 2010). In addition, other environmental factors such as high altitudes and increasing annual rainfall are also associated with the variable rates of the prevalence of CE in livestock (Acosta-Jamett et al., 2010; Fromsa and Jobre, 2011). Moreover, exposing of the parasite eggs to hostile environmental conditions will reduce their infective capacity (Torgerson et al., 1998).

The age of the intermediate hosts are largely recognised as an infection determinant for many animal species. Several studies have recorded higher CE prevalence in old animals compared to young ones (Islam et al., 2003; Banks et al., 2006; Lahmar et al., 2007; Christodoulopoulos et al., 2008). However, small animals like sheep and goats at the age of 3 years or over are at higher risk compared to the younger animals (Marshet et al., 2011). Furthermore, the number of hydatid cysts in infected animals has been reported to be related to the age of the animals (Cabrera et al., 1995; Umur and Kaaden, 2003; Ibrahim, 2010; Zewdu et al., 2010).

The highest rate of infection with CE was frequently observed with sheep and camels and they are found to be the most important intermediate hosts for $E$. granulosus (Himonas et al., 1994; Tashani et al., 2002; Grosso et al., 2012). It has been reported that, camels and cattle are usually slaughtered for meat production at older age than the other ruminants and because of this, they have an increased chance of exposure to $E$. granulosus' eggs and therefore they are at high risk during their lifetime. In comparison to sheep, camels and cattle, goats show a lower rate of infection with $\mathrm{CE}$ and this possibly because of their grazing type as they are browsers and eat the most distal parts of plants where there is a very little chance of exposure to the parasite eggs.

\section{Factors Influencing the Transmission of CE between Dogs and Livestock}

Cystic echinococcosis is one of the parasitic diseases occur in many species of farm animals in Libya with variable rates of infection, but it is observed more regularly associated with the level of infection with $E$. granulosus in dogs in each area. Camels are the most important host and sheep, goats and cattle comes second in the role of transmission and maintenance of $E$. granulosus in the country (Ibrahem and Gusbi, 1997). Many epidemiological factors are found to be associated 
with the increasing risk of $\mathrm{CE}$ in livestock, such factors include, hosts availability, the contamination level of the environment with the parasite eggs, livestock management, slaughtering of animals without meat inspection. Human behaviour also plays a key role in the distribution and transmission of cystic echinococcosis, such behaviour includes human cultural and economical backgrounds, (Dunn, 1979; Macpherson, 2005). In Libya, human behaviour play an important role in the increasing risk of infection with $\mathrm{CE}$ to livestock such as feeding of hydatid infected organs to dogs especially in socio-cultural occasions such as the festival of marriage and the religious day (EID Al-UDHA). During these occasions, hundreds of thousands of animals may be slaughtered in a single day under no veterinary inspection which therefore, maintains a highly infected dog population, the majority of which are farm and strays. In addition, lack of anti-helminthic treatment for infected dogs and dog owners' poor health education are all factors influencing the transmissions of $\mathrm{CE}$ between the definitive and intermediate hosts. However, general lack of people knowledge and awareness about infection factors may facilitate the transmission of $\mathrm{CE}$ in Livestock and the epidemiological models such as number and age of hosts, geographical location, species of hosts and the farming management type can identify them, (Otero-Abad and Torgerson, 2013).

\section{Economic Importance of Livestock Hydatidosis in Libya}

The levels of infection, particularly with $E$. granulosus hydatid cysts, impose an enormous medical, social and economic burden in the affected areas. Losses due to hydatid disease are largely economic through damage to domestic animals with the possible bans of import and export animals and their products especially from endemic areas (Battelli, 2009; Sariozkan and Yalcin, 2009).

For instance, previous reports from the abattoirs around the country showed high rates of infection with $\mathrm{CE}$ in slaughtered animals, however, such a situation has a critical economic impact due to the disease causing not only losses of internal animal organs and other products such as milk and meat, but also productivity in general (Lahmar et al., 1999).

Estimates of economic losses as a result of destroying the infected organs or the whole animal carcasses due to CE in Libya are not known because of the unavailability of governmental and abattoir records, however, the high level of infection with CE reported in livestock along the last few decades indicate the possible higher economic losses which may reach hundreds of thousands of Libyan dinars annually.

\section{Diagnosis of CE in Livestock}

Diagnosis of hydatid disease in livestock is usually based on post mortem investigation which provides an important epidemiological data that can be used to understand the level of infection pressure (Ming et al., 1992; Cabrera et al., 1995). Examination of the slaughtered animals viscera such as liver, lungs and other organs is the only practical way for the diagnosis of the hydatid disease, but the problem is that, very small lesions are not always be possible to discover or to differentiate from other helminthic parasites like Taenia hydatigena; therefore, extra histopathological investigation may be needed (Lloyd et al., 1991; Maxson et al., 1996). Some studies suggested the possibility of using ultrasonography to provide data on the number, size, site and condition of CE in sheep and goats (Maxson et al., 1996; Sage et al., 1998; Njoroge et al., 2000; Lahmar et al., 2007) and found to be a sensitive method for the diagnosis of liver CE in sheep. Using this technique alone or together with testing of biochemical parameters reflecting the liver functions could be helpful tools for the diagnosis of CE in the sheep liver, (Hussein and Elrashidy, 2014).

In comparison with human $\mathrm{CE}$, little researches have been employed on the development of immunodiagnostic techniques for CE infection in livestock. Development of sensitive and specific serological assay for the diagnosis of hydatid disease in livestock would provide useful epidemiological information for the ante-mortem study and for control of hydatid disease. Different diagnostic assays including, intradermal (Casoni) Test (ID), indirect immunoelectrophoresis (IEP), counter immunoelectrophoresis (CIEP), double diffusion (DD) and indirect haemagglutination (IHA), have been used for the serodiagnosis of $\mathrm{CE}$, but showed some cross-reactions with other Taeniid cestodes including, T. hydatigena and T. ovis (Yong et al., 1984; Lightowlers and Gottstein, 1995; Sbihi et al., 2001). Enzyme-linked immunosorbent assay (ELISA) is a technique developed for the diagnosis of parasitic diseases including $\mathrm{CE}$, although, many conflicting reports have been issued on the suitability of ELISA for the immunodiagnosis of hydatid disease (Farag et al., 1975; Iacona et al., 1980). Recent researches on the other hand suggested that, ELISA may be successfully performed for the diagnosis of hydatid disease as its sensitivity and reliability are related to the composition, concentration and stability of the antigen used (Sbihi et al., 2001; Ibrahem et al., 2002; Nasrieh and Abdel-Hafez, 2004).

Natural infection in livestock showed very poor antibody responses compared to that obtained in human infection (Lightowlers and Gottestein, 1995). In sheep, the main intermediate host for E. granulosus in most endemic regions of the world; antibodies to various parasitic antigens were detected in sera of some, but not 
all infected animals (Jenkins and Rickard, 1986). Detection of circulating antigen found to be useless for the diagnosis of $\mathrm{CE}$ in animals as it has been reported with human (Eckert et al., 2001b). Hydatid cyst fluid antigen B from camels and sheep, as well as a recombinant form of $\mathrm{AgB}(\mathrm{r}-\mathrm{AgB})$ has been used in an ELISA, to test serum samples from slaughtered camels and sheep naturally infected with $\mathrm{CE}$, the test seroreactivity, however, was variable. Antigen B from camel hydatid cyst fluid gave the highest test sensitivity $97 \%$ for camel CE and 92 to $95 \%$ for sheep CE from three origins (Libya, UK and Iran) while its specificity was $99 \%$ for both camel and sheep CE. Lower sensitivity $84 \%$ and $28 \%$ for camels and sheep CE respectively was obtained with r-AgB. r-AgB was, however, highly specific, yielding 90 and $95 \%$ for natural camels and sheep CE infections respectively (Ibrahem et al., 1996; 2002). A study carried out by Kittelberger et al. (2002) aimed to develop an immunological assay which would allow the monitoring of animals imported to countries free from hydatidosis and to help countries where control schemes for the disease are in operation. The study include three testing ELISAs, $8 \mathrm{kDa} \mathrm{AgB}$ from hydatid fluid (8kDa-ELISA), EG95 from oncospheres protein (Onco-ELISA) and crude protoscoleces preparation (Prot-ELISA), the tree assays used against sera from naturally or experimentally infected sheep with $\mathrm{CE}$ as well as from non-infected sheep. The highest sensitivity 51.4 to $62.7 \%$ was obtained with Prot-ELISA and the assay sensitivities being lower with $8 \mathrm{kDa}$-ELISA and Onco-ELISA. Diagnostic specificities with all three assays were very high 95.8 to $99.5 \%$, though a small number of serum samples from sheep infected with $T$. hydatigena and $T$. ovis were found to be seropositive. Due to its low diagnostic sensitivity, the assay would be only useful for the detection of the presence of infection in sheep on flock basis but not for reliable identification of individual animals. Antigenic characteristic of sheep hydatid cyst fluid was investigated by SDS-PAGE to evaluate its sensitivity and specificity in ELISA and immunoblotting against sheep CE and one antigen with molecular weight of $116 \mathrm{kDa}$ showed $88 \%$ sensitivity and $84 \%$ specificity in the immunoblot assay (Simsek and Koroghlu, 2004).

More recently, ELISA and Western Blotting (WB) have been evaluated for the serodiagnosis of CE in sheep and goats; the ELISA sensitivity was $66 \%$ in sheep and $54 \%$ in goats and the specificity was $86 \%$ in sheep and $73 \%$ in goats; while WB showed 71 and $69 \%$ sensitivity in sheep and goats respectively and 65 and $72 \%$ specificity in sheep and goats respectively, (Luka et al., 2008). In another study, it has been found that, 66 $\mathrm{kD}$ fraction of sheep hydatid cyst fluid is the best reactable part and the total $\mathrm{IgG}$ in sheep and cattle are the best antibodies for evaluation or diagnosing purposes, however, ELISA and western blotting are reliable enough when using sheep CHCF antigen as the source of antigen in either research or diagnostic evaluation programs (Fallah et al., 2014).

\section{Treatment of Cystic Hydatidosis in Livestock with Reference to Human Infection}

It has been identified by WHO-IWGE that, the best approach for treatment of CE in human should be based on the image and the cysts stage, which however, help in choosing one of the following treatment options; percutaneous, surgery, anti-infective drug or watch and wait (Brunetti et al., 2010). Puncture aspiration, reaspiration, injection and chemotherapy, also available for treatment (Pawloeski et al., 2001). Percutaneous drainage has many advantages and has been used in the treatment of $\mathrm{CE}$ in human as alternative to surgery (Yorganci and Sayek, 2002), however, with this method, it is impossible to remove cyst membranes, (laminar and germinative layers). The procedures of this method include puncture of the cyst wall, aspiration of its contents then injecting scolicidal agents and finally re-aspiration of the injecting fluid, as described by Ben-Amor et al. (1986), or by catheterization, as described by Akhan and Özmen (1999). Surgical procedures on the other hand start basically with inactivation of the cyst contents and finished with removal of all cyst components (Yorganci and Sayek, 2002; da Silva, 2003).

Chemotherapy as a treatment option of CE started decades ago when a new anti-helminthes drug was introduced. Benzimidazole and praziquantel as example of chemotherapy were introduced in the $1970 \mathrm{~s}$; the first has proved effective against the larval stages of $E$. granulosus in both animals and humans and the second found to be effective on protoscoleces (Heath and Chevis, 1974; Schantz et al., 1982). In addition to killing the entire larval stage of the parasite, benzimidazole also inhibit formation of microtubules, thus, reducing uptake of glucose and then interfere with the parasite homeostasis (Lacey, 1990).

Most studies indicate that, the effectiveness of albendazole on $\mathrm{CE}$ is generally less than $30 \%$ under ideal circumstances, however, continuous treatment with albendazole for a period of up to 6 months is recommended and praziquantel may increase the effect of treatment, especially in the case of cyst spillage (Teggi et al., 1993). Generally, 60\% of cysts show some response during the course of therapy, including shrinkage in size or separation of the cyst components from its wall. It has been suggested that, albendazole should be used on the daily bases for up to 4 to 6 weeks period and should be repeated further 2 to 3 times. 
Because the disease response to most chemotherapy treatment agents is poor, therefore, surgery is considered to be the principle treatment way for cystic echinococcosis. However, using chemotherapy remains an important tool for protection against spillage when removing the cysts, for the treatment of cases when surgery is difficult to perform, or for use in areas where sufficient surgical facilities are unavailable.

Oxfendazole like albendazole has been used in veterinary medicine to control nematode infections and both are similar in their antimicrobial spectra, but oxfendazole has a much longer half-life (Marriner and Bogan, 1980; 1981). In addition, oxfendazole, unlike albendazole, is effective against E. granulosus as well as other cestodes in the gastrointestinal tract (Gemmell et al., 1979) and thus could be used to treat infection in dogs, the principal reservoir for the infection to the intermediate hosts. Only one study has examined the effect of the drug on the tissue stage of tapeworm infections, this study showed that a single dose of 30 $\mathrm{mg} / \mathrm{kg}$ of body weight of oxfendazole in pigs completely eliminated all tissue cysts of Taenia solium, an important human tapeworm (Gonzales et al., 1996). Though, hydatid cyst is much larger than and structurally different from the cyst of cysticercosis, this result prompted a trial of oxfendazole for the treatment of hydatid disease. Similar studies carried out by Blanton et al. (1998) and Njoroge et al. (2005) using oxfendazole at the same dose on goats and sheep, the obtained results after postmortem examination showed that, 97 and $93.3 \%$ of the cysts contain dead protoscoleces or even absent compared to 28 and $27.3 \%$ of non treated cysts from control animals respectively. In addition, $53 \%$ of treated cysts found to be greatly degenerated and the cysts appeared to be potentially viable, there was sign of severe damage to its wall, the adventitial layer was severely disorganized with invasion of inflammatory cells and in some cases, the cysts were completely dead (Blanton et al., 1998). Further study on the evaluation of oxfendazole against $\mathrm{CE}$ in sheep showed decreasing in the number of fertile cysts and increasing in the number of degenerated cysts and it was more effectual 91.8-100\% against liver cysts and 49.6$61.2 \%$ against lung cysts (Gavidia et al., 2009).

Based on the reported findings, oxfendazole appeared to be encouraging drug for treatment of cystic hydatidosis and might be used for control programs as an additional strategy.

\section{Control and Prevention of Cystic Hydatidosis}

Different genotypes of E. granulosus spp. complex have been reported to be the cause of CE to humans and until now 10 genotypes have been characterized by using mitochondrial data. Such species complex involved 4 sub-species; E. granulosus sensu stricto, include sheep strain (G1), Tasmanian sheep strain (G2) and buffalo strain (G3); E. granulosus equines, include horse strain (G4); E. granulosus ortleppi, include cattle strain (G5) and E. granulosus Canadensis, include camel strain (G6), pig strain (G7 and G9) and cervid strain (G8 and G10) and among these genotypes G5 strain found to be genetically very distinct from the others (Thompson, 2008). In Libya, G1-G3 complex of E. granulosus sensu stricto and G6-G10 complex of E. granulosus canadenesis found to be the cause of most human cases (Abushhewa et al., 2010).

Cystic hydatid disease continues to be the major source of morbidity and mortality in many areas of the world. It is difficult to completely eliminate CE in the nearest time and by using the available control options, it will take decades of continuous attempts to achieving such a goal (Craig et al., 2007).

Dogs as the definitive hosts are the essential part in E. granulosus transmission to the intermediate hosts including humans and livestock, therefore, vaccination of dogs will provide efficient and cost-effective prevention programme. A study by Wenbao et al. (2006) revealed that, vaccination of dogs with soluble proteins from E. granulosus protoscoleces caused a significant suppression of both worm growth and egg production. In addition to vaccination, control plans needs to concentrate on careful analysis of the local situations such as the cycle, ecology and ethology of the animal hosts and the behavioural characteristics of the population at risk. Also using newly developed tools including immunology, molecular biology and imaging in both human and animals are important for each control programme. Moreover, control of slaughtering, anti-parasitic treatment, control of the definitive hosts, health education and vaccination of the intermediate hosts are very crucial in each control programme (Akira et al., 2003).

As it is difficult to completely avoid exposing to Echinococcus spp. eggs which are transmitted by a wild animals; therefore, precautions regarding food safety and good hygiene must be taken into consideration; in addition, all fruit and vegetable types especially those picked up from the wild, should be cleaned thoroughly with water to insure removing the parasite eggs if any. People who are dealing with handling pets, farming, gardening or preparing food, should wash their hands carefully before eating. Furthermore, fences should be built around vegetable and fruit gardens to keep dogs and other canids, away from the premises. Untreated water from sources such as lakes may also contain Echinococcus eggs and therefore should be avoided.

Unfortunately, there have been no $\mathrm{CE}$ control programmes in Libya in the past decades, but the high 
incidence of hydatid infection in human 1.4-2\% (Shambesh et al., 1999) and over 50\% in some species of livestock as reported by many researchers and the high rate of infection in dogs suggested the need for a control programme. Control programme is the most effective strategy when implemented on a community, area, or county-wide basis and must include; deworming of all dogs that may have access to livestock offal and this must be repeated at any time after any possible exposure. In some areas with a big problem with the parasite, programmes have been set up in which dogs are dosed praziquantel every 6 weeks. Proper disposal of dead animals or animal viscera containing hydatid disease to prevent dogs from access to eating it is another way of controlling the spread of the disease. Furthermore, elimination of stray dogs, keeping all dogs away from defecating in and around children's play areas, personal hygiene (hand washing) after handling or playing with dogs also help in reducing the chance of the disease endemicity.

There is a concern that, hydatidosis may have become hyper endemic in Libya due to the absence of any sign of attempt for control programme, also most of the slaughtered animals for meat consumption are occurred out of the government veterinary supervised abattoirs. There are evidences that, incidences of $\mathrm{CE}$ may have increased in the country in the last few years due to the major social and political changes as a result of the country government collapse; such changes could indirectly influence both veterinary and public health services.

Regular surveillance with serological tests can be helpful especially in high-risk populations who are in contact with the parasite eggs such as laboratory personnel and children who played with infected dogs and the purpose of such testing is to detect cysts in its early stages, when the treatment is more sufficient. Any control programme will be less effective without a support and commitment from dog-owners, who should have enough knowledge about the ways of disease transmission (David et al., 2006). Dosing of dogs with a suitable taeniacide must be involved in any control programme of hydatid disease especially in areas where home slaughter is more practiced (Watson-Jones and Macpherson, 1988). In developing countries, like Libya, effective destruction of infected offal and prevent canids from getting into the slaughterhouses will play an important role in reduction the incidence of CE in livestock (Fikire et al., 2012), as well as significantly reduce the disease transmission to the potential final hosts in the country.

The control procedures used to eliminate echinococcosis/hydatidosis from endemic areas are not adequately effective worldwide, however, vaccination of the grazing animals against infection with cystic echinococcosis is a further control method which targeted grazing animals instead of the dogs. Vaccination of the livestock may help in decreasing the transmission of the disease and hence reducing the prevalence of infection in human. Eg95 clone derived from E. granulosus oncospheres mRNA was tested and found to be most effective (Heath and Lawrence, 1996); this recombinant antigen has shown over $90 \%$ protection against challenge infections (Lightowlers et al., 1996). In a recent study, Eg95 approved for use on cattle, sheep, goats and camels and found to be very effective against hydatid disease as one dose provides up to $82 \%$ protection, two doses up to $97 \%$ and three doses up to $100 \%$ protection (Larrieu et al., 2015).

\section{Conclusion}

Cystic echinococcosis is prevalent in all domestic animals with variable rates of infection between the animal species and between the areas of Libya. According to the available data from abattoirs, the prevalence rate of infection with $\mathrm{CE}$ was ranged between 1.6 to $40 \%$ in sheep, 5.6 to $70 \%$ in goats, 2.7 to $56 \%$ in cattle and 2.7 to $48 \%$ in camels. Camels and sheep play an important role in the maintenance and transmission of the disease. Presented data describes the disease history along the last few decades in Libya and suggested that, the disease is continuing to spread throughout the country without any sign of control programme. Available abattoir records are important to report regularly the economic losses due to the infection with hydatid disease in livestock.

\section{Authors' Contributions}

Mohamed M. Ibrahem and Mostafa M. Abdorrahem: Developed the structure of the manuscript, carried out the literature research and draft the review.

Wafa M. Ibrahem and Kawther M. Ibrahem: Participated in co-wrote and organizes sections of the review and edited the overall manuscript.

\section{Ethics}

This review article is original and its contents have not been published before. It can be confirmed that all authors have read and approved the manuscript and no ethical issues involved.

\section{References}

Aboudaya, M.A., 1985. Prevalence of Echinococcus granulosus among domestic animals in Libya. Trop. Anim. Health Prod., 17: 169-70.

DOI: $10.1007 /$ BF02355879 
Abushhewa, M.H., M.J. Nolan, A.R. Jex, B.E. Campbell and A. Jabbar et al., 2010. Genetic classification of Echinococcus granulosus cysts from humans, cattle and camels in Libya using mutation scanning-based analysis of mitochondrial loci. Mol. Cell. Prob., 24: 346-351.

DOI: $10.1016 /$ j.mcp.2010.07.005

Acosta-Jamett, G., S. Cleavel, A.A. Cunningham, B.M.C. Bronsvoort and P.S. Craig, 2010. Echinococcus granulosus infection in humans and livestock in the Coquimbo region, north-central Chile. Vet. Parasitol., 169: 102-110.

DOI: $10.1016 /$ j.vetpar.2009.12.009

Akhan, O. and M.N. Ozmen, 1999. Percutaneous treatment of liver hydatid cysts. Eur. J. Rad., 32: 76-85. DOI: 10.1016/S0720-048X(99)00116-3

Akira, I., U. Carlo, J. Qiu, A.V. Dominique and D. Qiu et al., 2003. Control of echinococcosis and cysticercosis: A public health challenge to international cooperation in China. Act. Trop., 86: 3-17. DOI: 10.1016/S0001-706X(02)00269-3

Al-Khalidi, N.W., 1998. Cystic echinococcosis (hydatidosis) in sheep, goats, cattle and camels in Shahat abattoir, Al-Jabal, Libya. Proceedings of the 3rd Annual Meeting for Animal Production Under Arid Conditions, (UAC; 98), United Arab Emirates University, pp: 143-149.

Ansari-Lari, M., 2005. A retrospective survey of hydatidosis in livestock in Shiraz, Iran, based on abattoir data during 1999-2004. Vet. Parasitol., 133: 119-123. DOI: 10.1016/j.vetpar.2005.05.031

Bal, N., E. Nazim, R.A. Kocer, A. Ezer and K. Fazilet, 2008. Uncommon locations of hydatid cyst. Saudi Med. J., 29: 1004-1008. PMID: 18626530

Banks, D.J.D., D.B. Copeman, L.F. Skerratt and E.C. Molina, 2006. Echinococcus granulosus in northern Queensland. 1. Prevalence in cattle. Aust. Vet. J., 84: 303-307. DOI: 10.1111/j.1751-0813.2006.00020.x

Ben-Amor, N., M. Gargouri, H.A. Gharbi, Y.J. Golvan and K. Ayachi et al., 1986. Trial therapy of inoperable abdominal hydatid cysts by puncture. Ann. Parasitol. Hum. Comp., 61: 689-692. PMID: 3566087

Blanton, R.E., T.M. Wachira, E.E. Zeyhle, E.M. Njoroge and J.K. Magabo et al., 1998. Oxfendazole treatment for cystic hydatid disease in naturally infected animals. Antimicrob. Agents Chemother., 42: 601-605. PMID: 9517939

Brunetti, E., P. Kern and D.A. Vuitton, 2010. Expert consensus for the diagnosis and treatment of cystic and alveolar echinococcosis in humans. Act. Trop., 114: 1-16.

DOI: $10.1016 /$ j.actatropica.2009.11.001
Cabrera, P.A., G. Haran, U. Benavidez, S. Valledor and G. Perera et al., 1995. Transmission dynamics of Echinococcus granulosus, Taenia hydatigena and Taenia ovis in sheep in Uruguay. Int. J. Parasitol., 25: 807-813. DOI: 10.1016/0020-7519(94)00209-7

Battelli, G., 2009. Echinococcosis: Costs, losses and social consequences of a neglected zoonosis. Vet. Res. Commun., 33: S47-S52.

DOI: $10.1007 / \mathrm{s} 11259-009-9247-y$

Christodoulopoulos, G., G. Theodoropoulos and G. Petrakos, 2008. Epidemiological survey of cestodelarva disease in Greek sheep flocks. Vet. Parasitol., 153: 368-373. DOI: 10.1016/j.vetpar.2008.02.002

Cicogna, D., 1961. Lechinociccosi in Tripolitania. Boll. San. Del. Trip., 2: 3-3.

Craig, P.S., D.P. McManus, M.W. Lightwolers, J.A. Chabalgoity and H.H. Garcia et al., 2007. Prevention and control of cystic echinococcosis. Lat. Inf. Dis., 7: 385-394. DOI: $10.1016 / \mathrm{S} 1473-3099(07) 70134-2$

Dalimi, A., G. Motamedi, M. Hosseini, B. Mohammadian and H. Malaki et al., 2002. Echinococcosis/hydatidosis in western Iran. Vet. Parasitol., 105: 161-171. DOI: 10.1016/S03044017(02)00005-5

Daryani, A., R. Aiaei, R. Arab and M. Sharif, 2006. Prevalence of hydatid cyst in slaughtered animals in Northwest Iran. J. Anim. Vet. Adv., 5: 330-334.

David, H., Y. Wen, L. Tiaoying, X. Yongfu and C. Xingwang et al., 2006. Control of hydatidosis. Parasitol. Int., 55: 247-252. DOI: $10.1016 /$ j.parint.2005.11.052

Dunn, F.L., 1979. Behavioural aspects of the control of parasitic diseases. Bul. Wold Health Org., 57: 499-512. PMID: 316733

Eckert, J., P. Deplazes, P.S. Craig, M. Gemmell and B. Gottstein et al., 2001a. Echinococcosis in Animals: Clinical Aspects, Diagnosis and Treatment. In: WHO/OIE Manual on Echinococcosis in Humans and Animals: A Public Health Problem of Global Concern, Eckert, J., M.A. Gemmell, F.X. Meslin and Z.S. Pawlowski (Eds.), W.O. Anim. Hlth, Paris, France, pp: 72-99.

Eckert, J., P.M. Schantz, R.B. Gasser, P.R. Torgerson and A.S. Bessonov et al., 2001b. Geographic Distribution and Prevalence. In: WHO/OIE Manual on Echinococcosis in Humans and Animals: A Public Health Problem of Global Concern, Eckert, J., M.A. Gemmell, F.X. Meslin and Z.S. Pawlowski (Eds.), W.O. Anim. Hlth, Paris, France, pp: 101-143.

Eckert, J. and P. Deplazes, 2004. Biological, epidemiological and clinical aspects of echinococcosis, a zoonosis of increasing concern. Clin. Microb. Rev., 17: 107-125 
Ekhnefer, A.M.H., 2014. Prevalence of cystic echinococcosis infestation sheep, goats and cattle in the Bayda city- Libya. Am. J. Res. Comm., 2: 11-22.

Elmajdoub, L.O.M., K.M. El-Hoti and N.M. Hadid, 2007. Prevalence of hydatid disease in slaughtered livestock animals from Misurata abattoir- Libya. J. Un. Arab Bio., 28A: 163-174.

Elmajdoub, L.O.M. and W.A. Rahman, 2015. Prevalence of hydatid cysts in slaughtered animals from different areas of Libya. Open J. Vet. Med., 5: 1-10. DOI: $10.4236 /$ ojvm.2015.51001

Ernest, E., H.E. Nonga, A.A. Kassuku and R.R. Kazwala, 2009. Hydatidosis of slaughtered animals in Ngorongoro district of Arusha region, Tanzania. Trop. Anim. Health Prod., 41: 1179-1185. PMID: 19105043

Fallah, M., A. Khosravi, A. Shamsi, H. Maghsood and A. Bahrami et al., 2014. Effectiveness of sheep Crude Hydatid Cyst Fluid (CHCF) antigen for serodiagnosis of human, sheep, mice and cattle hydatidosis. Adv. Res. Agric. Vet. Sc., 1: 12-17.

Farag, H., D. Bout and A. Capron, 1975. Specific immunodiagnosis of human hydatidosis by the Enzyme Linked Immunosorbent Assay (E.L.I.S.A.). Biomedicine, 23: 276-278. PMID: 782577

Fikire, Z., T. Tolosa, C. Macias and N. Kebede, 2012. Prevalence and characterization of hydatidosis in animals slaughtered at Addis Ababa Abattoir, Ethiopia. Eth. J. Parasitol. Vect. Biol., 4: 1-6. DOI: $10.5897 /$ JPVB1 1.020

Fromsa, A. and Y. Jobre, 2011. Infection prevalence of hydatidosis (Echinococcus granulosus, Batsch, 1786) in domestic animals in Ethiopia: A synthesis report of previous surveys. Eth. Vet. J., 15: 11-33. DOI: $10.4314 /$ evj.v15i2.67691

Gavidia, C.M., A.E. Gonzalez, L. Lopera, C. Jayashi and R. Angelats et al., 2009. Evaluation of nitazoxanide and oxfendazole efficacy against cystic echinococcosis in naturally infected sheep. Am. J. Trop. Med. Hyg., 80: 367-372. PMID: 19270283

Gebreel, A.O., H.M. Gilles and J.E. Prescott, 1983. Studies on the sero-epidemiology of endemic diseases in Libya. I. Echinococcosis in Libya. Ann. Trop. Med. Parasitol., 77: 391-397. PMID: 6639185

Gemmell, M.A., P.D. Johnstone and G. Oudemans, 1979. The effect of oxfendazole on Echinococcus granulosus and Taenia hydatigena infections in dogs. Res. Vet. Sc., 26: 389-390. PMID: 515529

Gonzales, A.E., H.H. Garcia, R.H. Gilman, C.M. Gavidia and V.C.W. Tsang et al., 1996. Effective, singledose treatment or porcine cysticercosis with oxfendazole. Am. J. Trop. Med. Hyg., 54: 391-394. PMID: 8615453
Grosso, G., S. Gruttadauria, A. Biondi, S. Marventano and A. Mistretta, 2012. Worldwide epidemiology of liver hydatidosis including the Mediterranean area. Wold. J. Gastro., 18: 1425-1437. DOI: $10.3748 /$ wjg.v18.i13.1425

Gusbi, A.M., M.A. Awan and W.N. Beesley, 1987. Echinococcosis in Libya. II. Prevalence of hydatidosis (Echinococcus granulosus) in sheep. Ann. Trop. Med. Parasitol., 81: 35-41. PMID: 3675041

Gusbi, A.M., M.A.Q. Awan and W.N. Beesley, 1990. Echinococcosis in Libya. IV. Prevalence of hydatidosis (Echinococcus granulosus) in goats, cattle and camels. Ann. Trop. Med. Parasitol., 84: 477-82. PMID: 2256770

Heath, D.D. and R.A.F. Chevis, 1974. Mebendazole and hydatid cysts. Lancet, $2: 218-9$. DOI: 10.1016/S0140-6736(74)91517-7

Hussein, A.H. and M. Elrashidy, 2014. Ultrasonographic features of the liver with cystic echinococcosis in sheep. Vet. Rec. Open, 1: e000004-e000004. DOI: 10.1136/vropen-2013-000004

Heath, D.D. and S.B. Lawrence, 1996. Antigenic polypeptides of Echinococcus granulosus oncospheres and definition of protective molecules. Parasite Immunol., 18: 347-357. DOI: 10.1046/j.1365-3024.1996.d01-114.x

Himonas, C., E. Antoniadou-Sotiriadou and E. Papadopoulos, 1994. Hydatidosis of food animals in Greece: Prevalence of cysts containing viable protoscoleces. J. Helminth., 68: 311-313. DOI: $10.1017 / \mathrm{S} 0022149 \mathrm{X} 00001541$

Iacona, A., C. Pini and G. Vicari, 1980. Enzyme-Linked Immunosorbent Assay (ELISA) in the serodiagnosis of hydatid disease. Am. J. Trop. Med. Hyg., 29: 95-102. PMID: 6986099

Ibrahem, M.M., P.S. Craig, A. McVie, K. Ersfeld and M.T. Rogan, 1996. Echinococcus granulosus antigen B and seroreactivity in natural ovine hydatidosis. Res. Vet. Sci., 61: 102-106. DOI: 10.1016/S0034-5288(96)90082-X

Ibrahem, M.M. and A.M. Gusbi, 1997. Cystic Echinococcosis in North Africa (Excluding Morocco): Veterinary Aspects. In: Compendium on Cystic Echinococcosis in Africa and in Middle Eastern Countries with Special Reference to Morocco anderson, F.L., H. Ouhelli and M. Kachani, (Eds). Brigham Young University, Provo, UT., pp: 207-222.

Ibrahem, M.M. and P.S. Craig, 1998. Prevalence of cystic echinococcosis in camels (Camelus dromedarius) in Libya. J. Helminth., 72: 27-31. DOI: $10.1017 / \mathrm{S} 0022149 \mathrm{X} 00000936$ 
Ibrahem, M.M., A. Rafiei, F.K. Dar, S.M. Azwai and S.D. Carter et al., 2002. Serodiagnosis of cystic echinococcosis in naturally infected camels. Parasitology, 125: 245-251.

DOI: $10.1017 / \mathrm{S} 0031182002002044$

Ibrahem, M.M. and W.M. Ibrahem, 2015. Incidence of cystic echinococcosis in Libya: I. Seroprevalence of hydatid disease in sheep and goats naturally exposed to the infection in the North West region. J. Parasit. Dis. (in press).

Ibrahim, M., 2010. Study of cystic echinococcosis in slaughtered animals in Al Baha region, Saudi Arabia: Interaction between some biotic and abiotic factors. Act. Trop., 113: 26-33.

DOI: $10.1016 /$ j.actatropica.2009.08.029

Islam, M.K., S.C. Basak, S. Majumder, S.A. Sarder and A.W.M.S. Islam et al., 2003. Cystic echinococcosis in domestic ruminants in Cox's Bazar of Bangladesh. Pak. J. Sc. Ind. Res., 46: 251-254.

Jenkins, D.J. and M.D. Rickard, 1986. Specific antibody responses in dogs experimentally infected with Echinococcus granulosus. Am. J. Trop. Med. Hyg., 35: 345-349. PMID: 3953947

Kassem, A.H. and N.K. Gdoura, 2006. Hydatidosis in camels (Camelus dromedarius) slaughtered at Sirt abattoir, Libya. J. Egypt. Soc. Parasitol., 36: 1-10. PMID: 17366866

Kassem, A.H., A. Abdul-kader and S.A. Nass, 2013. Prevalence of hydatid cysts in slaughtered animals in Sirte, Libya. J. Egypt. Soc. Parasitol., 43: 33-40. DOI: $10.12816 / 0006365$

Kittelberger, R., M.P. Reichel, J. Jenner, D. Heath and M.W. Lightowlers et al., 2002. Evaluation of three enzyme-linked immunosorbent assays (ELISAs) for the detection of serum antibodies in sheep infected with Echinococcus granulosus. Vet. Parasitol., 110: 57-76. DOI: 10.1016/S0304-4017(02)00308-4

Lacey, E., 1990. Mode of action of benzimidazoles. Parasitol. Today, 6: 112-5.

DOI: 10.1016/0169-4758(90)90227-U

Lahmar, S., M. Kilani, P.R. Torgerson and M.A. Gemmell, 1999 Echinococcus granulosus larvae in the livers of sheep in Tunisia: The effects of host age. Ann. Trop. Med. Parasitol., 93: 75-81.

DOI: $10.1080 / 00034989958825$

Lahmar, S., H. Debbeka, L.H. Zhang, D.P. McManus and A. Souissi et al., 2004. Transmission dynamics of the Echinococcus granulosus sheep-dog strain (G1 genotype) in camels in Tunisia. Vet. Parasitol., 121: 151-156. DOI: 10.1016/j.vetpar.2004.02.016

Lahmar, S., F. Ben Chehida, A.F. Petavy, A. Hammou and J. Lahmar et al., 2007. Ultrasonographic screening for cystic echinococcosis in sheep in Tunisia. Vet. Parasitol., 143: 42-49.

DOI: 10.1016/j.vetpar.2006.08.001
Larrieu, E., G. Mujica, C.G. Gauci, K. Vizcaychipi and M. Seleiman et al., 2015. Pilot field trial of the EG95 vaccine against ovine cystic echinococcosis in Rio Negro, Argentina. PLoS. Neg. Trop. Dis., 9: e0004134- e0004134. DOI: 10.1371 journal.pntd.0004134

Lightowlers, M.W. and B. Gottstein, 1995. Echinococcosis/Hydatidosis: Antigens, Immunological and Molecular Diagnosis, In: The Biology of Echinococcus and Hydatid Disease, Thompson, R.C.A. and A.J. Lymbery (Eds.), CAB International, Allingford, United Kingdom, pp: 355-410.

Lightowlers, M.W., S.B., Lawrence, C.G. Gauci, J. Young and M.J. Ralston et al., 1996. Vaccination against hydatidosis using a defined recombinant antigen. Parasite Immunol., 18: 457-462. DOI: $10.1111 /$ j.1365-3024.1996.tb01029.x

Lloyd, S., S.C. Martin, T.M.H. Walters and E.J.L. Soulsby, 1991. Use of sentinel lambs for early monitoring of the South Powys hydatidosis control scheme: Prevalence of Echinococcus granulosus and some other helminths. Vet. Rec., 129: 73-76.

DOI: $10.1136 /$ vr.129.4.73

Luka, S., I. Ajogi, I. Nock, C. Kudi and J. Umoh, 2008. Evaluation of enzyme-Linked Immunosorbent Assay (ELISA) and western blotting for the immunodiagnosis of hydatid diseases in sheep and goats. Int. J. Vet. Med., 5: 1-6.

Macpherson, C.N.L., L. Karstad, P. Stevenson and J.H. Arundel, 1983. Hydatid disease in the Turkana District of Kenya. III. The significance of wild animals in the transmission of Echinococcus granulosus, with particular reference to Turkana and Masailand in Kenya. Ann. Trop. Med. Parasitol., 77: 66-73. PMID: 6882057

Macpherson, C.N.L., 2005. Human behaviour and the epidemiology of parasitic zoonoses. Int. J. Parasitol., 35: 1319-1331. DOI: 10.1016/j.ijpara.2005.06.004

Marshet, E., K. Asamre, J. Bekele, T. Anteneh and M. Abera et al., 2011. The status of cystic echinococcosis (hydatidosis) in small ruminants slaughtered at Addis Ababa municipal abattoir. J. Anim. Vet. Adv., 10: 1445-1449. DOI: 10.3923/javaa.2011.1445.1449

Marriner, S.E. and J.A. Bogan, 1980. Pharmacokinetics of albendazole in sheep. Am. J. Vet. Res., 41: 1126-1129. PMID: 7436109

Marriner, S.E. and J.A. Bogan, 1981. Pharmacokinetics of oxfendazole in sheep. Am. J. Vet. Res., 42: 1143-1145. PMID: 7271032

Maxson, A.D., T.M. Wachira, E.E. Zeyhle, A. Fine and T.W. Mwangi et al., 1996. The use of ultrasound to study the prevalence of hydatid cysts in the right lung and liver of sheep and goats in Turkana, Kenya. Int. J. Parasitol., 26: 1335-1338. DOI: 10.1016/S0020-7519(96)00124-5 
McManus, D.P., W. Zhang, J. Li and P.B. Bartley, 2003. Echinococcosis. Lancet, 362: 1295-1304. DOI: 10.1016/S0140-6736(03)14573-4

Medulla, C., 1931. La Cirenaica del punto di vista Sanitario. Arch. Ital. Sci. Med. Colo., 12: 391-418.

da Silva, A.M., 2003. Hydatid cyst of the liver- criteria for the selection of appropriate treatment. Act. Trop., 85: 237-242. DOI: $10.1016 / \mathrm{S} 0001-706 \mathrm{X}(02) 00271-1$

Ming, R., T.H. Dennis, F.L. Andersen, J. Chai and Y. Sultan, 1992. Frequency distribution of Echinococcus granulosus hydatid cysts in sheep populations in the Xinjiang Uygur Autonomous Region, China. Vet. Parasitol., 44: 67-75. DOI: 10.1016/0304-4017(92)90144-X

Nasrieh, M.A. and S.K. Abdel-Hafez, 2004. Echinococcus granulosus in Jordan: Assessment of various antigenic preparations for use in the serodiagnosis of surgically confirmed cases using enzyme immuno assays and the indirect haemagglutination test. Dia. Microb. Inf. Dis., 48: 117-123. DOI: 10.1016/j.diagmicrobio.2003.09.018

Njoroge, E.M., P.M.F. Mbithi, J.M. Gathuma, T.M. Wachira and J.K. Magambo et al., 2000. Application of ultrasonography in prevalence studies of hydatid cysts in goats in north-western Turkana, Kenya and Toposaland, southern Sudan. Ond. J. Vet. Res., 67: 251-255.

Njoroge, E.M., P.M.F. Mbithi, J.M. Gathuma, T.M. Wachira and P.B. Gathura et al., 2002. A study of cystic echinococcosis in slaughter animals in three selected areas of Northern Turkana, Kenya. Vet. Parasitol., 104: 85-91.

DOI: $10.1016 / \mathrm{S} 0304-4017(01) 00614-8$

Njoroge, E.M., P.M.F. Mbithi, T. Wachira, J.M. Gathuma and P. Gathura et al., 2005. Comparative study of albendazole and oxfendazole in treatment of cystic echinococcosis in sheep and goats. Int. J. Appl. Res. Vet. Med., 3: 97-101. Otero-Abad, B. and P. R. Torgerson, 2013. A systematic review of the epidemiology of echinococcosis in domestic and wild animals. PLOS Neg. Trop. Dis., 7: 1-13. DOI: 10.1371/journal.pntd.0002249

Pawloeski, Z.S., J. Eckert, D.A. Vuiton, R.W. Ammann and P. Kern et al., 2001. Echinococcosis in Humans: Clinical Aspects, Diagnosis and Treatment. In: Manual on Echinococcosis in Humans and Animals: A Public Health Problem of Global Concern, Eckert, J. M.A. Gemmell, Meslin and Z.S. Pawloeski (Eds.), WHO/OIE pp: 20-66.

Polat, P., K. Mecit, A. Fatih, S. Selami and B.K. Melike et al., 2003. Hydatid disease from head to toe. Rad. Graph., 23: 475-494. PMID: 12640161
Sage, A.M., T.M. Wachira, E.E. Zeyhle, E.P. Weber and E. Njoroge et al., 1998. Evaluation of diagnostic ultrasound as a mass screening technique for the detection of hydatid cysts in the liver and lung of sheep and goats. Int. J. Parasitol., 28: 349-353. DOI: 10.1016/S0020-7519(97)00187-2

Sariozkan, S. and C. Yalcin, 2009. Estimating the production losses due to cystic echinococcosis in ruminants in Turkey. Vet. Parasitol., 163: 330-334. DOI: 10.1016/j.vetpar.2009.04.032

Sbihi, Y., A. Rmigui, M.N. Rodriquez-Cabezas, A. Orduna and A. Rodrigues-Torres et al., 2001. Comparative sensitivity of six serological tests and diagnostic value of ELISA using purified antigen in hydatidosis. J. Clin. Lab. Anal. 15: 14-18.

DOI: $\quad 10.1002 / 1098-2825(2001) 15: 1<14:: A I D-$ JCLA3>3.0.CO;2-7

Schantz, P.M., H. Van den Bossche and J. Eckert, 1982. Chemotherapy for larval echinococcosis in animals and humans: Report of a workshop. Zo. Parasit., 53: 5-26. DOI: 10.1007/BF00929509

Shambesh, M.K., P.S. Craig, C.N.L. Macpherson, M.R. Rogan and A.M. Gusbi et al., 1999. An extensive ultrasound and serologic study to investigate the prevalence of human cystic echinococcosis in northern Libya. Am. J. Trop. Med. Hyg., 60: 462-468. PMID: 10466978

Simsek, S. and E. Koroghlu, 2004. Evaluation of Enzyme-Linked Immunosorbent Assay (ELISA) and Enzyme-linked Immunoelectrotransfer Blot (EITB) for immunodiagnosis of hydatid diseases in sheep. Act. Trop., 92: 17-27.

DOI: $10.1016 /$ j.actatropica.2004.04.006

Tashani, O.A., L.H. Zhang, B. Boufana, A. Jegi and D.P. McManus, 2002. Epidemiology and strain characteristics of Echinococcus granulosus in the Benghazi area of eastern Libya. Ann. Trop. Med. Parasitol., 96: 369-381. DOI: $10.1179 / 000349802125000952$

Teggi, A., M.G. Lastilla and F. De Rosa, 1993. Therapy of human hydatid disease with mebendazole and albendazole. Ant. Agen. Chemoth., 37: 1679-84. DOI: 10.1128/AAC.37.8.1679

Thompson, R.C.A., 1995. Biology and Systematics of Echinococcus. In: The Biology of Echinococcus and Hydatid Disease, Thompson, R.C.A. and A.J. Lymbery (Eds.), CAB International, Wallingford, United Kingdom, pp: 1-50.

Thompson, R.C.A., 2008. The taxonomy, phylogeny and transmission of Echinococcus. Exp. Parasitol., 119: 439-446. DOI: 10.1016/j.exppara.2008.04.016

Torgerson, P.R., D.H. Williams and M.N. Abo-Shehada, 1998. Modelling the prevalence of Echinococcus and Taenia species in small ruminants of different ages in northern Jordan. Vet. Parasitol., 79: 35-51. DOI: 10.1016/S0304-4017(98)00157-5 
Umur, S. and O.R. Kaaden, 2003. Prevalence and economic importance of cystic echinococcosis in slaughtered ruminants in Burdur, Turkey. J. Vet. Med. Se., B, 50: 247-252. PMID: 12864901

Watson-Jones, D.L. and C.N.L Macpherson, 1988. Hydatid disease in the Turkana district of Kenya. VI. Man:dog contact and its role in the transmission and control of hydatidosis amongst the Turkana. Ann. Trop. Med. Parasitol., 82: 343-356. PMID: 3252758

Wenbao, Z., Z. Zhuangzhi, S. Baoxin, L. Jun and Y. Hong et al., 2006. Vaccination of dogs against Echinococcus granulosus the cause of cystic hydatid disease in humans. J. Inf. Dis., 194: 966-974. DOI: $10.1086 / 506622$

Yong, W.K., D.D. Heath and F.V. Knapen, 1984. Comparison of cestode antigens in an enzymelinked immunosorbent assay for the diagnosis of Echinococcus granulosus, Taenia hydatigena and T. ovis infections in sheep. Res. Vet. Sci., 36: 24-31. PMID: 6200907
Yorganci, K. and I. Sayek, 2002. Surgical treatment of hydatid cysts of the liver in the era of percutaneous treatment. Am. J. Surg. 184: 63-69. DOI: $10.1016 / \mathrm{S} 0002-9610(02) 00877-2$

Zhang, W., J. Li and D.P. McManus, 2003. Concepts in immunology and diagnosis of hydatid disease. Clin. Microb. Rev., 16: 18-36.

DOI: $10.1128 / C M R .16 .1 .18-36.2003$

Zewdu, E, Y. Teshome and A. Makwoya, 2010. Bovine hydatidosis in Ambo municipality abattoir, West Shoa, Ethiopia. Eth. Vet. J., 14: 1-14. 